\title{
Effect of nutrition on seasonal patterns of LH, FSH and testosterone concentration, testicular mass, sebaceous gland volume and odour in Australian cashmere goats
}

\author{
S. W. Walkden-Brown ${ }^{1 *}$, B. J. Restall ${ }^{2}$, B. W. Norton ${ }^{1}$, \\ R. J. Scaramuzzi ${ }^{3 \dagger}$ and G. B. Martin ${ }^{4,5}$ \\ ${ }^{I}$ Department of Agriculture, University of Queensland, QLD 4072, Australia; ${ }^{2}$ Wollongbar Agricultural \\ Institute, NSW Agriculture, Wollongbar, NSW 2477, Australia; ${ }^{3}$ CSIRO Division of Animal Production, \\ Prospect, NSW 2148, Australia; ${ }^{4}$ Animal Science Group, Faculty of Agriculture, University of Western \\ Australia, Nedlands, WA 6009, Australia; and ${ }^{5}$ CSIRO Division of Animal Production, Wembley, \\ WA 6014, Australia
}

The effects of season and diet on LH, FSH and testosterone concentrations, testicular mass, sebaceous gland volume and male odour were examined in mature Australian cashmere goat bucks fed ad libitum with diets of low or high quality for 16 months under natural photoperiod at $29^{\circ} \mathrm{S}, 153^{\circ} \mathrm{E}$ ( $n=6$ per treatment). Each week plasma was sampled, the bucks were weighed, scored for male odour and assessed for testicular mass based on scrotal circumference. Each month a skin sample was taken from the occipital region for histological assessment of sebaceous gland volume. For each variable there was a clear circannual cycle that was significantly influenced by dietary treatment. In bucks fed the low-quality diet, the timing of seasonal changes in LH and testosterone concentration, sebaceous gland volume and odour score was similar, with a mid-autumn peak. In each case the high-quality diet advanced, extended the duration and increased the magnitude of the seasonal increase. FSH concentrations peaked in late spring (in bucks on the high-quality diet) or summer (in bucks on the low-quality diet), reaching a nadir in early winter. The high-quality diet significantly increased concentrations only in the last 2 months of the experiment (spring). There was no overall association between these variables and change in testicular mass; instead, it was strongly correlated with voluntary feed intake and change in body mass, themselves subject to seasonal variation with a winter or spring peak. The high-quality diet induced large increases in body mass and testicular mass during the first months of the experiment without influencing the seasonally low concentrations of FSH, LH and testosterone present at the time. These results demonstrate that the male, like the female, Australian cashmere goat, exhibits marked reproductive seasonality, and that nutrition is a powerful modulator of the seasonal cycle. They suggest that testosterone concentration, sebaceous gland volume and odour score are ultimately dependent upon LH secretion, which appears to be under strong seasonal (photoperiodic) control, with the effects of enhanced nutrition limited to periods when photoperiodic inhibition is waning. However, seasonal regulation of testicular mass, and therefore sperm production, appears to be primarily dependent on changes in voluntary feed intake and growth, with the seasonal cycle of testicular mass more a consequence of the seasonal appetite or growth cycle than of changing gonadotrophin concentrations.

\section{Introduction}

For all species, a balance must be achieved between reproductive strategies based on either opportunism or seasonal

\footnotetext{
*Current address: Animal Science Group, Faculty of Agriculture, University of Western Australia, Nedlands WA 6009, Australia.

${ }^{\dagger}$ Current address: Department of Veterinary Basic Sciences, Royal Veterinary College, University of London, London, UK.

Received 11 April 1994.
}

cueing (Bronson, 1985). Opportunistic breeders will mate whenever environmental conditions are good, while seasonal breeders restrict mating to a time that will result in optimal conditions for the rearing of the young - the most physiologically demanding event of the reproductive cycle. Changing photoperiod is the most common environmental cue used to regulate reproduction in seasonal breeders (Clarke, 1981), but many species and strains do not fit neatly into a seasonal or opportunistic classification because, for them, the timing of 
reproductive events is determined by complex interactions between photoperiodic, social and nutritional cues. While most studies investigating these interactions to date have used small rodent species more suited to opportunistic strategies (e.g. Irby et al., 1984; Wayne and Rissman, 1990; Wayne et al., 1991), few have been carried out on larger, more strongly photoperiodic species.

The goat, like the sheep, is classified as seasonally polyoestrous and photoperiod is the primary environmental cue used to regulate reproduction (Bissonnette, 1941). This seasonality is strongly present in female Australian cashmere goats and the feral goats from which they are derived (Harrington, 1982; Restall, 1992). Nevertheless, it is increasingly evident that social and nutritional cues are also important regulators of the seasonal reproductive cycle in this species. For example, seasonally anovulatory does can be induced to ovulate in response to the sudden introduction of males (the so-called male effect), with the magnitude of the response influenced by both season (Chemineau, 1987; Restall, 1992) and the nutritional status of the male (Walkden-Brown et al, 1993). Bucks exposed to females in oestrus also exhibit an increase in gonadotrophin and testosterone secretion (the so-called female effect); the response depends upon season (Howland et al., 1985). In addition, drought-breaking rain and the associated increase in the availability of feed can initiate reproductive activity in Australian feral goats (Harrington, 1982), and prevailing nutritional conditions also appear to influence reproductive activity in less seasonal tropical goats (GonzalezStagnaro, 1983).

On the basis of this knowledge, we hypothesized that mature bucks maintained under ambient photoperiod and fed diets of different quality would exhibit a circannual pattern of variation in reproductive activity, the timing and magnitude of which would be influenced by both the quality of diet and exposure to females in oestrus. These hypotheses were tested in an experiment using mature Australian cashmere goats. In this paper, we report the effects of nutrition on gonadotrophin concentrations, testicular function and some secondary sexual characteristics.

\section{Materials and Methods}

\section{Location and animals}

The experiment was carried out at the Wollongbar Agricultural Institute, Wollongbar $\left(28^{\circ} 48^{\prime} \mathrm{S}, 153^{\circ} 25^{\prime} \mathrm{E}\right)$. Hours of daylight (sunrise to sunset) vary from $10.3 \mathrm{~h}$ at the winter solstice (June 21) to $14.0 \mathrm{~h}$ at the summer solstice (December 22), while mean minimum and maximum temperatures range from 8.9 and $17.6^{\circ} \mathrm{C}$ in July to 18.5 and $26.4^{\circ} \mathrm{C}$ in January. The experimental animals $(n=12)$ were drawn from a random-bred line of domesticated feral goats. They were 34 months old and had all previously been used for breeding. The history and management of the goat population at Wollongbar has been described by Restall and Pattie (1989).

\section{Experimental procedure}

Bucks were individually housed in $2.0 \mathrm{~m} \times 2.5 \mathrm{~m}$ pens under natural photoperiod for 16 months between 1 July and 13
October of the following year. The experiment commenced when body mass was at its seasonal nadir for bucks at pasture in this environment. All bucks were offered an introductory diet of $1.2 \mathrm{~kg}$ pelleted lucerne (Medicago sativa) and coarsely hammermilled pangola grass (Digitaria decumbens) hay day ${ }^{-1}$ in equal parts for 10 days, before they were divided into two treatment groups stratified on body mass and libido. One group (Low) was fed a low-quality diet of hammermilled pangola grass hay (crude protein: $6.9 \%$; metabolizable energy: $6.6 \mathrm{MJ} \mathrm{kg}^{-1}$ ) ad libitum, while the other group (High) was fed a high-quality diet of pelleted lucerne (crude protein: $17.6 \%$; metabolizable energy: $8.3 \mathrm{MJ} \mathrm{kg}^{-1}$ ) ad libitum for the remainder of the experiment. The diets and their digestibility, together with data on voluntary feed intake and growth, have been described by Walkden-Brown et al. (1994a).

Each week the bucks were sampled for plasma, weighed and the scrotal circumference was measured. Each month a skin biopsy was taken to assess sebaceous gland activity. Every second month blood samples were collected at intervals of $20 \mathrm{~min}$ over two $8 \mathrm{~h}$ periods, with each buck exposed to a female in oestrus throughout the second period. The acute effects of females in oestrus on pulsatile hormone secretion have been reported separately by Walkden-Brown et al. (1994b). In early October it was noted that the bucks in the High group began exhibiting a strong buck odour, while those in the Low group did not; therefore, in each week thereafter the odour was evaluated subjectively. This was done by smelling the dorsum of the neck $10-15 \mathrm{~cm}$ immediately posterior to the base of the horns, where the male odour was strongest, and allocating a score of 0 (neutral odour, no different from a female or a castrated male), 1 (mild male odour), 2 (moderate male odour) or 3 (strong male odour). These measurements were highly repeatable within operators and were carried out by a single operator for the entire experiment.

Weekly plasma samples for LH, FSH and testosterone assay comprised pooled aliquots from three jugular blood samples collected at intervals of $40 \mathrm{~min}$. The scrotal circumference was measured to the nearest $0.1 \mathrm{~cm}$ in the standing animal using a light elastic band placed around the neck of the scrotum to seat the testes in the scrotum. The scrotal skin was clipped every 6 weeks. Skin samples were collected with a $1 \mathrm{~cm}$ trephine at random from a region $5 \mathrm{~cm}$ wide on the dorsal aspect of the neck, between 5 and $10 \mathrm{~cm}$ posterior to the base of the horns.

\section{Radioimmunoassay}

The LH and testosterone assays are described in detail by Walkden-Brown et al. (1994b). LH was assayed in duplicate using a heterologous double-antibody radioimmunoassay with caprine LH standards (Henniawati, 1993; immunopotency: $0.208 \times \mathrm{NIH}-\mathrm{oLH}-\mathrm{S} 20$ ) and rabbit antiserum directed against ovine $\mathrm{LH}$. The mean ( \pm SEM) assay sensitivity was $1.33 \pm 0.14 \mu \mathrm{g} \mathrm{l}^{-1}$. The mean intra-assay coefficients of variation were $12.3,8.1$ and $6.3 \%$ for samples containing 3.0, 12.0 and $36.0 \mu \mathrm{g} \mathrm{l}^{-1}$, respectively, while the mean interassay coefficients of variation were $21.9,7.8$ and $6.6 \%$, respectively. Testosterone was assayed in duplicate using a single antibody radioimmunoassay after extraction with hexane. The mean ( \pm SEM) assay sensitivity was $0.08 \pm 0.01 \mu \mathrm{g} \mathrm{l}^{-1}$. The mean 

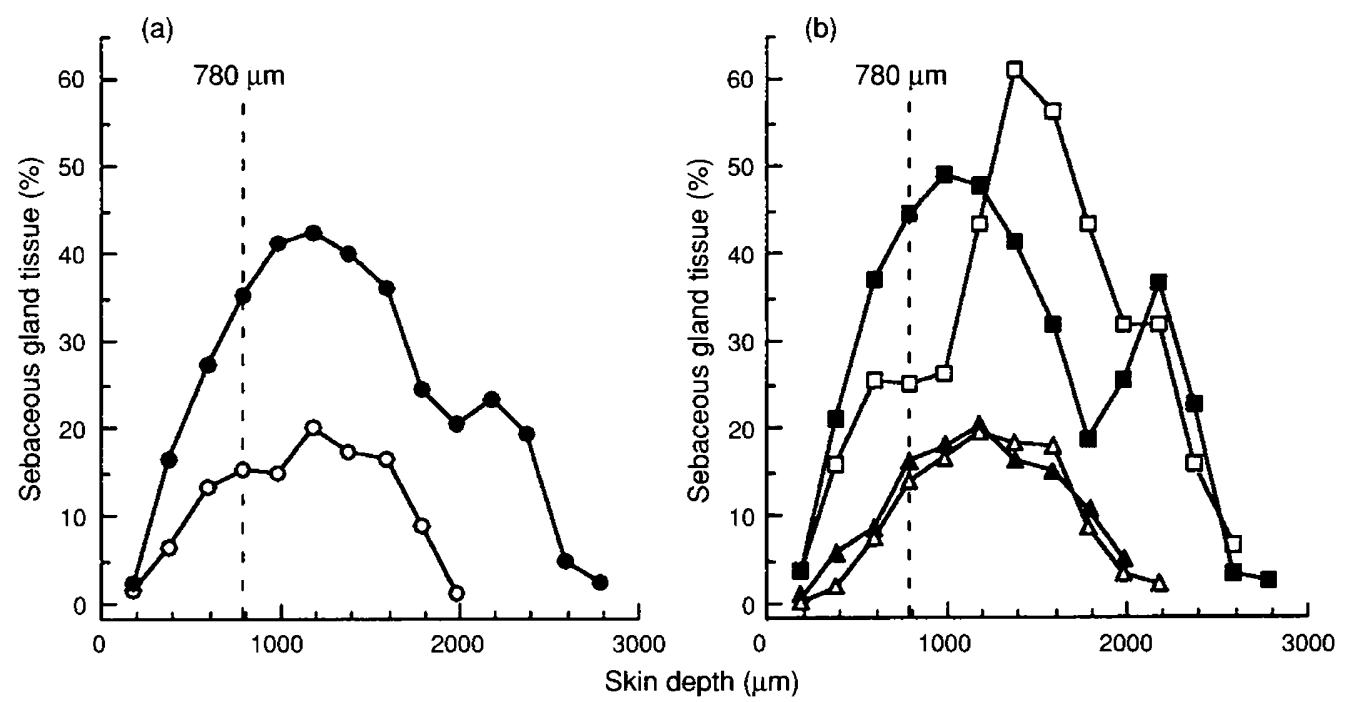

Fig. 1. Effect of (a) diet and (b) time of year on the proportion of sebaceous gland tissue at different depths in buck skin sections. Skin biopsies were performed on bucks fed diets of low $(0 ; n=2)$ or high $(\bullet ; n=2)$ quality from the occipital region in January $(\square)$, April $(\boldsymbol{\square})$, July $(\triangle)$ and October $(\Delta)$. The area under the curves represents the total volume of sebaceous tissue in the sections.

intra-assay coefficients of variation for quality controls containing $0.38,2.89$ and $8.19 \mu \mathrm{g} \mathrm{I}^{-1}$ were $16.9,9.4$ and $8.1 \%$, respectively, while the mean interassay coefficients were 12.7 , 7.2 and $6.7 \%$, respectively.

FSH samples were assayed in duplicate in a single assay, using an ovine radioimmunoassay described and validated for goats by Miller and Martin (1993). The standard used was NIAMDD-oFSH-RP-I, and the limit of assay sensitivity was $0.13 \mu \mathrm{g} \mathrm{l}^{-1}$. The mean intra-assay coefficients of variation for quality controls containing $1.45,2.61$ and $4.24 \mu \mathrm{g} \mathrm{I}^{-1}$ were $13.9,8.6$ and $9.0 \%$, respectively.

\section{Determination of sebaceous gland volume}

Skin samples were fixed in buffered $10 \%$ formalin before being dehydrated, cleared and embedded with paraplast in an automated sample processor. Sections, $10 \mu \mathrm{m}$ thick, were cut and stained with haematoxylin and eosin. The total volume of sebaceous gland in a single section, as a percentage of the total volume of the section, was determined by volumetric analysis using differential point counting as described by Weibel $e t$ al. (1966). Sebaceous gland tissue was readily identified on the basis of staining and morphological characteristics (Maddocks and Jackson, 1988). Counts were made on five different fields selected at random within each of five distinct zones on the circular section (lower, central, upper, right, left), and covered a minimum of $16.7 \%$ of the total area of the section. To estimate the total sebaceous gland volume in a skin sample, sections at $180 \mu \mathrm{m}$ depth in the skin and at $200 \mu \mathrm{m}$ intervals thereafter were examined as described above. The total volume of sebaceous gland in each sample was then determined using the following formula:

$$
V_{\text {tot }}=\left(\Pi r^{2}\right) \times\left(D_{1}-D_{n}\right) \times\left(\Sigma V_{1} \ldots n / 100 s\right) \times\left(R^{3} / r^{3}\right),
$$

where $V_{\text {tot }}$ is the total volume of sebaceous gland in sample $\left(\mathrm{mm}^{3}\right)$, corrected for shrinkage due to fixation, $r$ is the mean radius of $n$ sections $(\mathrm{mm}), D_{1} \ldots n$ is the depth in $\mathrm{mm}$, of sections $1 \ldots n, V_{1 \ldots n}$ is the percentage of sebaceous gland tissue in equally spaced sections $1 \ldots n, s$ is the number of counted sections containing sebaceous tissue, and $R$ is the radius of sections prior to fixing $(0.5 \mathrm{~cm})$.

The value $\left(R^{3} / r^{3}\right)$ is a correction factor for shrinkage in cross-sectional area and depth for the sample.

The measurement of $V_{\text {tot }}$ is time consuming, so an attempt was made to identify an accurate indirect measure of this variable in a preliminary study. $V_{\text {tot }}$ was measured in 16 skin samples selected to provide maximum variation (Fig. 1). The samples were from four individual bucks (two from each diet group); a sample from October, January, April and July was taken from each buck. The relationship between total sebaceous gland volume in a sample and the relative volume of sebaceous gland at various depths in the sample was then examined. The percentage of sebaceous tissue at a skin depth of $780 \mu \mathrm{m}\left(V_{780}\right)$ was the best fixed depth predictor of $V_{\text {tot }}$, with a strong linear relationship between the two variables $\left(V_{\text {tot }}=-5.04+1.26 \times V_{780} ; R^{2}=0.874 ; \quad P<0.001\right)$. Consequently, all further samples were measured for sebaceous gland volume at a skin depth of $780 \mu \mathrm{m}$.

\section{Derived variables}

Testicular mass. Testicular mass was estimated from scrotal circumference measurements, using the equation:

$$
P T M=21.5 S C-323.7 \text {, }
$$

where PTM is the paired testicular mass in $g$, and $S C$ is the scrotal circumference in $\mathrm{cm}\left(R^{2}=0.88 ; n=75 ; P<0.001\right.$; Walkden-Brown et al., 1994c). The transformed variable was used because it is more informative, and enables direct comparisons of the magnitude of change in body mass and testicular mass to be made. 
Daily change in testicular mass. The daily change in testicular mass was derived from weekly data smoothed using the Lowess smoothing algorithm to reduce error associated with measurement (Cleveland, 1981). The smoothed data provided an excellent fit of the data within bucks and removed the majority of the apparently random noise in the series, accounting for $86.1 \pm 0.05 \%$ of the variation within bucks, and $97 \%$ of the total experimental variation in testicular mass. However, the unsmoothed data were used for the analysis of testicular mass.

\section{Statistical analyses}

Weekly data $(n=67)$ were grouped into monthly means (calendar months; $n=16$ ) for each buck. These means, and records of any monthly measurements, were then subjected to repeated measures analysis of variance (Wilkinson, 1990). Log transformation of the hormone data to correct for heterogeneity of variance did not alter the conclusions of the analysis, so the analysis of the untransformed data is presented for ease of interpretation. Associations between variables over time were examined with standard linear correlation methods, using monthly treatment means (within treatments: $n=16$; pooled: $n=32$ ). In the text, means are presented with the standard error of the mean.

\section{Results}

\section{Plasma concentrations of $L H, F S H$ and testosterone}

For all three hormones, there was a significant effect of month $(P<0.001)$ and a significant interaction between the effects of month and diet $(P<0.05 ;$ Fig. $2 a, b, c)$. In the case of testosterone, the overall effect of diet was also significant $(P<0.05)$.

FSH concentrations varied seasonally in both treatments, reaching a peak value in late spring (High) or summer (Low) and reaching a nadir in late autumn or early winter (Fig. 2a). Diet only affected FSH concentration in the final 2 months of the experiment, with significantly higher concentrations in bucks in the High group $(P<0.05)$.

LH concentrations showed significant seasonal variation, rising in both treatments in late spring and falling during late autumn to a winter nadir (Fig. 2b). Diet affected the magnitude of the seasonal rise in bucks in the High group, with these bucks having significantly higher concentrations in November and May $(P<0.05)$. The concentrations of $\mathrm{LH}$ and FSH were correlated in bucks on the low-quality $(r=0.79, P<0.001)$ but not the high-quality diet $(r=0.46$, not significant).

Fig. 2. Monthly means ( \pm SEM) of plasma concentrations of (a) FSH, (b) LH and (c) testosterone, (d) the percentage of sebaceous gland tissue at a skin depth of $780 \mu \mathrm{m}$ in samples taken from the occipital region and (e) odour score for 3 -year-old cashmere bucks fed diets of low $(0 ; n=6)$ or high $(* n=6)$ quality ad libitum under natural photoperiod at $29^{\circ} \mathrm{S}$ for 16 months. The dashed curve represents the annual curve of photoperiod (units not shown; range: $10.3-14.0 \mathrm{~h}$ ). (a)

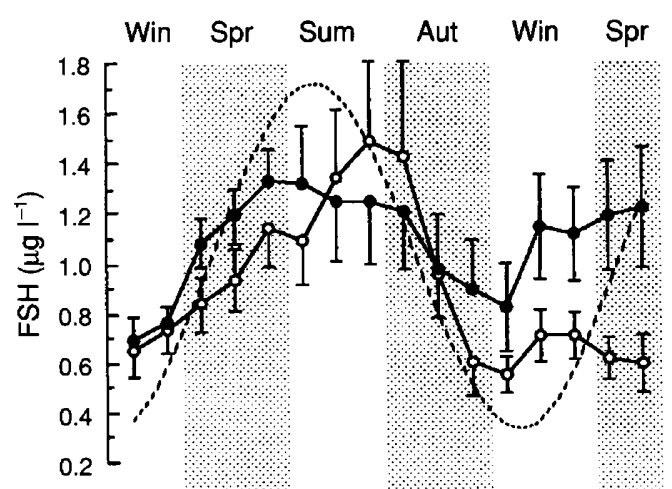

(b)

(c)

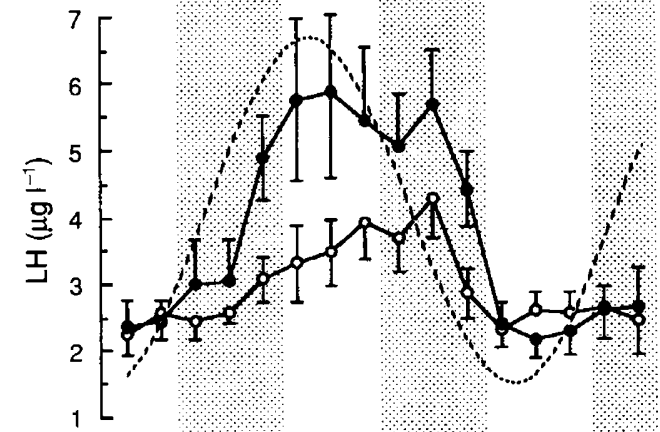

(d)
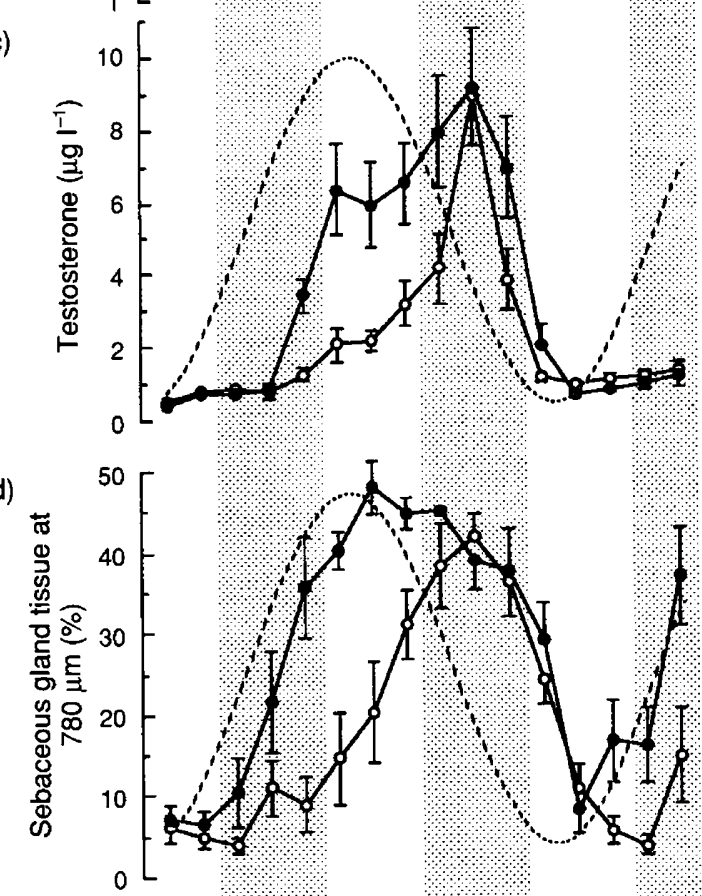

(e)

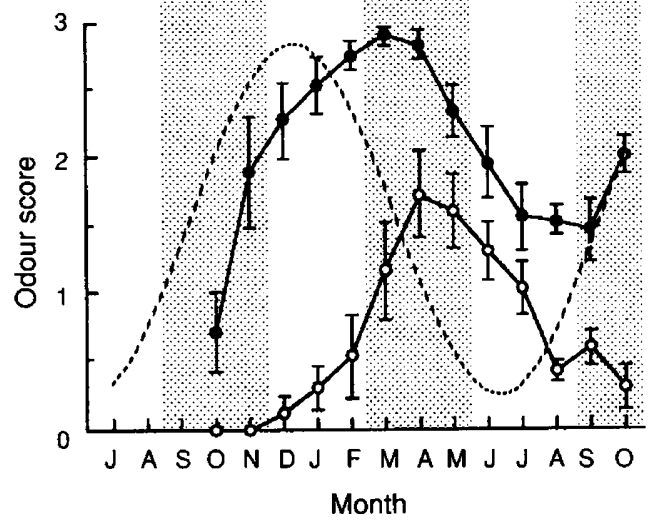


Testosterone concentrations showed a marked seasonal profile in both dietary treatments, closely paralleling, but of greater amplitude than, that of LH (Fig. 2c). The effect of diet on the seasonal pattern was also more pronounced, with significantly higher concentrations occurring in bucks on the high-quality diet from November to February $(P<0.05)$. The concentration of testosterone was strongly correlated with $\mathrm{LH}$ concentration within both treatments (Low: $r=0.82$; High: $r=0.91 ; P<0.001)$ and overall $(r=0.87, P<0.001)$, but was not correlated with FSH concentration (Low: $r=0.33$; High: $r=0.23$; not significant).

\section{Sebaceous gland volume}

The volume of sebaceous gland tissue was significantly influenced by diet and month of measurement, with significant interaction between the two effects $(P<0.001$; Fig. $2 \mathrm{~d})$. There was marked seasonal variation in both treatments that was similar to that observed for $\mathrm{LH}$ and testosterone. Bucks on the high-quality diet had significantly higher sebaceous gland volumes than did those on the low-quality diet from November to February and from August to October in the second year $(P<0.05)$. Sebaceous gland volume was strongly and positively correlated with $\mathrm{LH}$ and testosterone concentrations within dietary treatments (Low: $r=0.73$ and 0.84 , respectively; $P<0.001$; High: $r=0.84$ and 0.83 , respectively; $P<0.001)$ and overall $(r=0.80$ and 0.84 , respectively; $P<0.001$ ), but was not correlated with FSH concentration in either treatment.

\section{Odour score}

Both diet and month of measurement influenced the odour score significantly, with significant interaction between these effects $(P<0.001 ;$ Fig. 2e). There was a clear seasonal pattern in odour score in both treatments, with scores peaking in autumn and reaching a nadir in late winter or early spring. Bucks fed the high-quality diet had significantly higher odour scores $(P<0.05)$ than did those fed the low-quality diet in all months except June and July of the second year. Odour score was positively correlated with testosterone concentration and sebaceous gland size within treatments (Low: $r=0.65$ and 0.73 , respectively; $P<0.05$; High: $r=0.88$ and 0.82 , respectively; $n=13 ; P<0.001)$ and overall $(r=0.71$ and 0.79 , respectively; $n=26 ; P<0.001$ ).

\section{Body mass}

There were significant effects of both diet and month on body mass and the change in body mass, with significant interaction between these effects $(P<0.001$; Fig. 3a,c). Bucks in

Fig. 3. Monthly means ( \pm SEM) for (a) body mass, (b) paired testicular mass, (c) change in body mass, (d) change in testicular mass and (e) the ratio of testicular to body mass for 3-year-old cashmere bucks fed diets of low $(0 ; n=6)$ or high $(\bullet ; n=6)$ quality ad libitum under natural photoperiod at $29^{\circ} \mathrm{S}$ for 16 months. The dashed curve represents the annual curve of photoperiod (units not shown; range: $10.3-14.0 \mathrm{~h}$ ) (a)

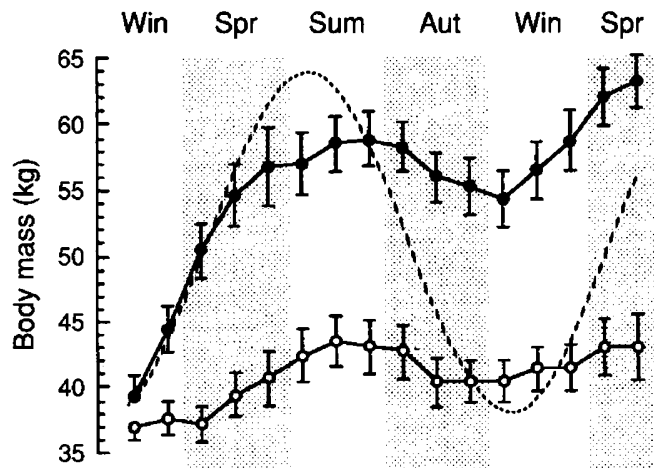

(b)

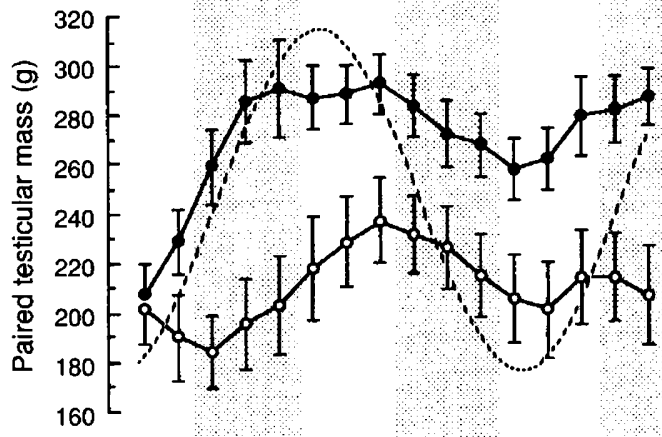

(c)

(d)
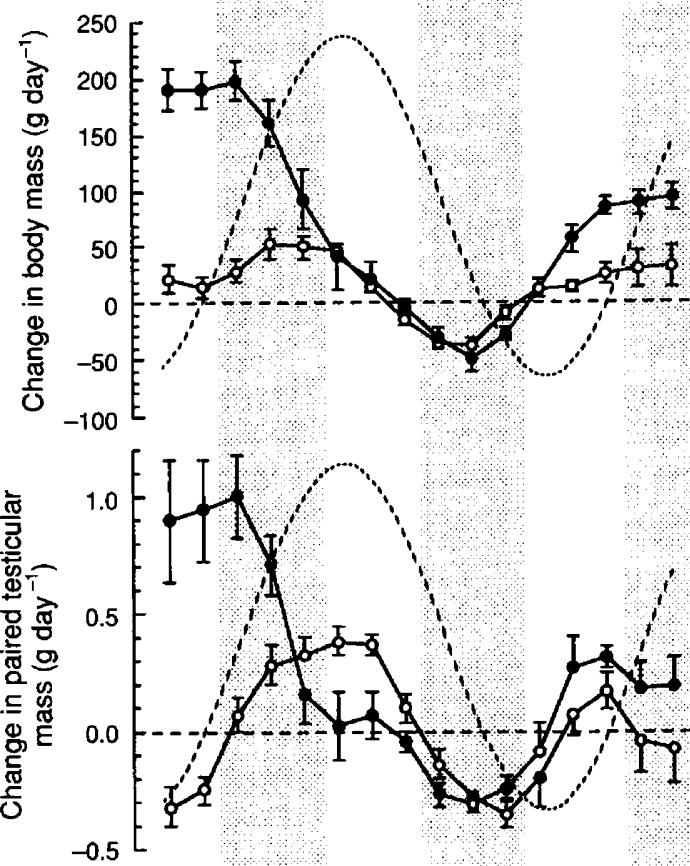

(e)

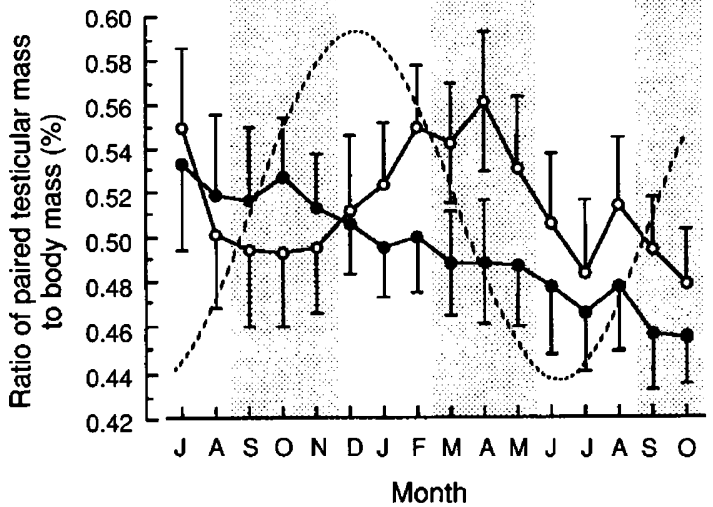



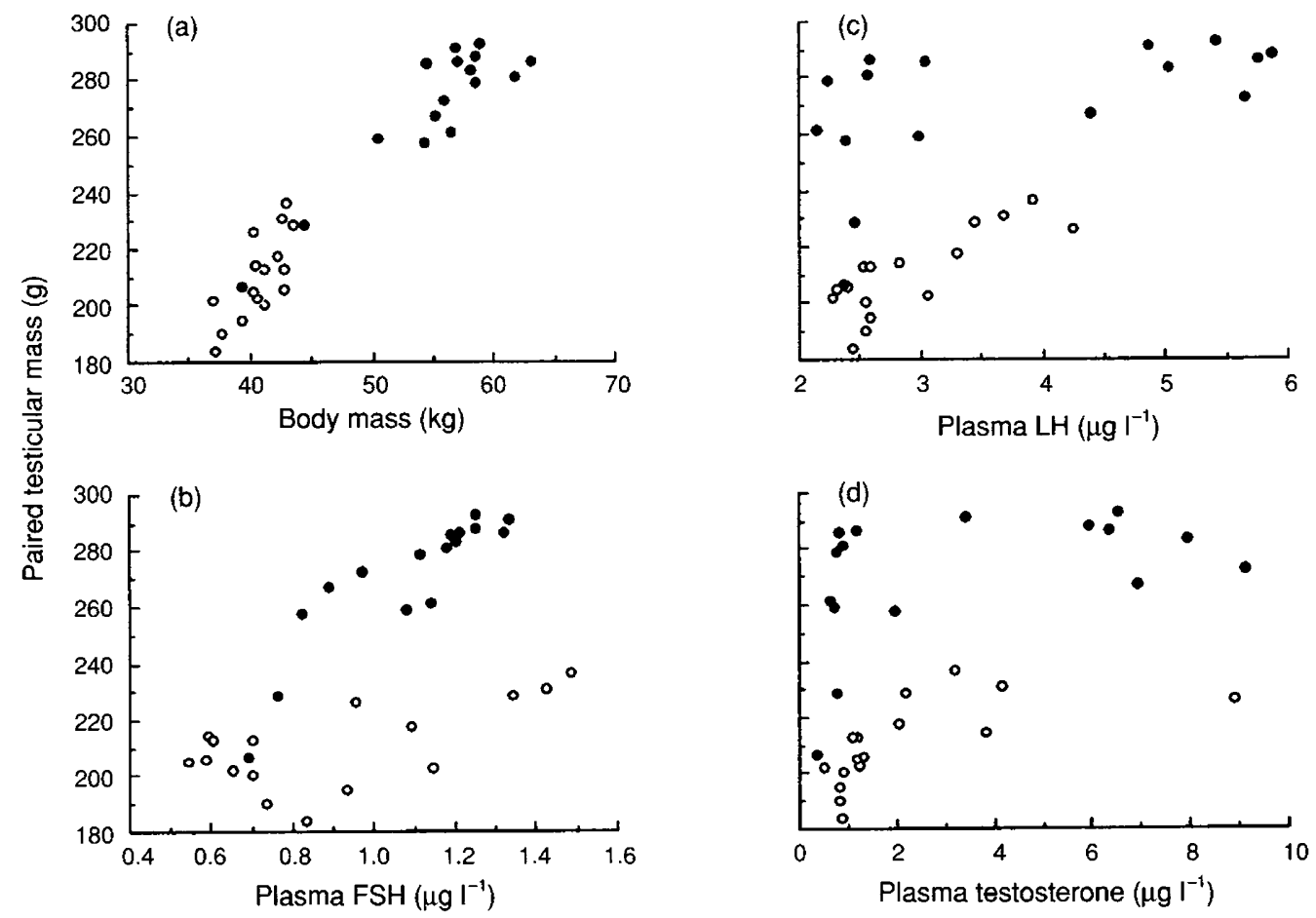

Fig. 4. Association between paired testicular mass and (a) body mass, and mean plasma concentrations of (b)

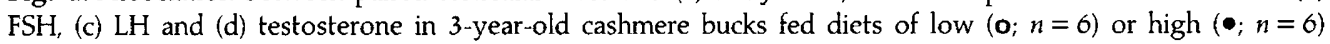
quality ad libitum under natural photoperiod at $29^{\circ} \mathrm{S}$ for 16 months. Each point represents a monthly mean for one of the diets (overall, $n=32$ ).

both treatment groups exhibited a seasonal growth cycle characterized by weight loss during autumn, despite free access to the diets. The effect of diet was seasonally dependent, with the high-quality diet enhancing growth significantly only from July to October in both years.

\section{Testicular mass}

Testicular mass was influenced by both $\operatorname{diet}(P<0.05)$ and month of measurement $(P<0.001)$, with significant interaction between these effects $(P<0.001$; Fig. $3 b)$. Seasonal change was evident in both treatment groups, with the pattern of change closely following that of body mass, peaking in summer and reaching a nadir in winter. Testicular mass was greater in bucks fed the high-quality diet for all but the first 2 months of the experiment and during April $(P<0.05)$.

Testicular mass was strongly correlated with body mass both within treatments (Low: $r=0.74$; High: $r=0.92$; $P<0.001)$ and overall $(r=0.96 ; P<0.001$; Fig. 4a). Correlations with gonadotrophin concentrations varied with treatment (LH: Low, $r=0.80, P<0.001$; High, $r=0.52, P<0.05$; FSH: Low, $r=0.62, P<0.05$; High, $r=0.89, P<0.001$ ) and the overall association was only moderate (LH: $r=0.59$; FSH: $r=0.62 ; P<0.001$; Fig. $4 \mathrm{~b}, \mathrm{c})$.

Change in testicular mass was significantly higher in bucks on the high-quality diet compared with those on the lowquality diet during the first 4 months of the experiment (July-October), but over the following 3 months (NovemberJanuary) the reverse was true $(P<0.05$; Fig. $3 \mathrm{~d})$. Beyond
January, there were no significant differences between the treatments in any month

Daily change in testicular mass was positively correlated with digestible organic matter intake and daily change in body mass within treatments (Low: $r=0.86, P<0.001$ and $r=0.56$, $P<0.05$, respectively; High: $r=0.89$ and $0.99, P<0.001$, respectively) and overall ( $r=0.85$ and $0.89, P<0.001$ respectively; Fig. 5a,b). Overall, there was no association between change in testicular mass and the concentration of LH, FSH or testosterone, but significant associations were found within treatment groups (Fig. $5 \mathrm{c}$,d). In bucks on the low-quality diet, change in testicular mass was positively correlated with FSH $(r=0.50 ; P<0.05)$, but not $\mathrm{LH}$ or testosterone concentrations. In bucks fed the high-quality diet, it was negatively correlated with $\mathrm{LH}$ and testosterone concentrations $(r=-0.58$ and -0.74 , respectively; $P<0.05)$ and there was no association with FSH.

Because paired testicular mass was so closely associated with body mass, the ratio of the two variables was examined to determine whether the association was modulated by season or diet. It was significantly influenced by month of measurement $(P<0.001)$, and there was a significant interaction between the effects of month and diet $(P<0.001)$ (Fig. 3e). There was a significant seasonal shift in the ratio in bucks on the low-quality diet with a peak in late summer and autumn, while in bucks fed the high-quality diet the ratio was stable over the first 4 months before declining continuously throughout the rest of the experiment. The ratio was not significantly correlated with any hormone in bucks on the high-quality diet, but was 

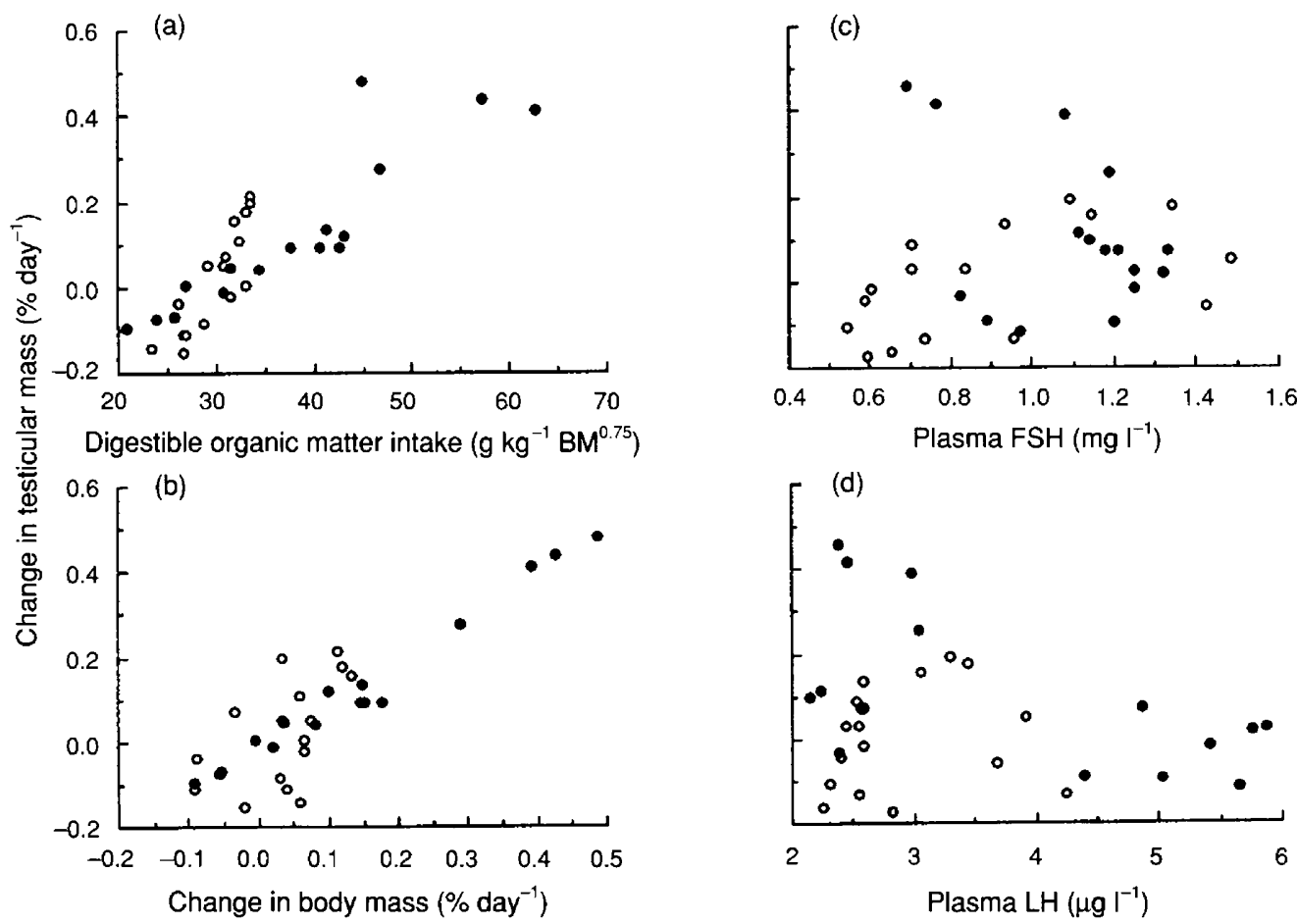

Fig. 5. Association between change in paired testicular mass and (a) digestible organic matter intake, (b) change in body mass and mean plasma concentrations of (c) FSH and (d) LH in 3-year-old cashmere bucks fed diets of low $(0 ; n=6)$ or high $(\bullet ; n=6)$ quality ad libitum under natural photoperiod at $29^{\circ} \mathrm{S}$ for 16 months. Each point represents a monthly mean for one of the diets (overall, $n=32$ ).

correlated with LH $(r=0.65 ; \quad P<0.05)$ and testosterone $(r=0.69 ; P<0.01)$, but not with FSH $(r=0.43$; not significant $)$ concentrations in bucks on the low-quality diet.

\section{Discussion}

The effects of season and diet on hormone concentrations and secondary sexual characteristics in this study are best considered in relation to two fundamental seasonal cycles, both of them subject to modulation by prevailing nutritional conditions. The first of these cycles is a reproductive cycle driven by changing secretion of gonadotrophins (Walkden-Brown et al., 1994b), while the second is an appetite or growth cycle driven by unknown factors (Walkden-Brown et al., 1994a). Most of the variables examined appeared to be driven by secretion of pituitary gonadotrophins, in particular $\mathrm{LH}$, forming a cascade of dependent effects through testosterone secretion, sebaceous gland size and odour score. However, testicular mass did not fit into this cascade and appeared to be influenced primarily by changes in the appetite or growth cycle with some modulation by gonadotrophins.

The seasonal profile of FSH, LH and testosterone concentrations observed in bucks on the constant low-quality diet is in broad agreement with that observed in other studies in goats (Muduuli et al., 1979; Howland et al., 1985; Ritar, 1991), and seasonal breeds of sheep (Lincoln and Short, 1980; D'Occhio and Brooks, 1983; Lincoln et al., 1990). In rams, such changes are driven by changing photoperiod and mediated primarily by changes in the frequency of pulses of GnRH released from the hypothalamus (Lincoln and Short, 1980). In goats, photoperiod also drives reproductive seasonality (Bissonnette, 1941; Delgadillo and Chemineau, 1992), and seasonal changes in LH pulse frequency suggest that the effects of photoperiod are at least partly driven by changing GnRH secretion (Howland et al., 1985; Ritar, 1991; Walkden-Brown et al., 1994b). That the seasonal testosterone cycle closely followed that of $\mathrm{LH}$ is not surprising given the dependence of testosterone on $\mathrm{LH}$ secretion. The greater amplitude of the testosterone cycle compared with that of LH is probably due to seasonal changes in testicular responsiveness to $\mathrm{LH}$, with greatly enhanced responsiveness during the autumn rut (Walkden-Brown et al., $1994 \mathrm{~b})$. The seasonal pattern of sebaceous gland volume closely matched that of testosterone since these glands are regulated by androgens (Ebling, 1957; Jenkinson et al., 1967). During the period when the sebaceous gland was large it was noticeable that the fleece of the bucks, particularly in the neck region, became greasy with sebum. This sebum had an extremely strong, unpleasant buck odour and changes in its secretion were almost certainly responsible for the seasonal changes in odour in the bucks (Jenkinson et al., 1967; Sasada et al., 1983). The precise functions of this seasonal pattern of sebaceous gland size in the buck, and the associated changes in odour, remain obscure. There is evidence that the odour of buck fleece contributes to the ovulatory response of does to the introduction of bucks (Shelton, 1980; Claus et al., 1990), and it has been postulated that combinations of odours from male urine and fleece may signal the metabolic status of one male to 
others (Coblentz, 1986). It is also possible that, in common with many other ungulates, these odours play a role in the marking of territory (Müller-Schwarze, 1991) or in the recognition of individuals (Beauchamp et al., 1976).

The effects of diet on testosterone secretion, sebaceous gland size and odour score all appear to flow from the season-dependent effect of diet on LH secretion. For each of these variables, the effect of the high-quality diet was to advance, extend the duration of and increase the magnitude of the seasonal rise, with the greatest effect occurring during the summer months. Nutritional effects on the secretion of $\mathrm{LH}$ have been reported in many species, and most studies have demonstrated an inhibitory effect of undernutrition at the hypothalamus (I'Anson et al., 1991). Fewer studies have examined the effects of enhanced nutrition. In Merino rams, supplementation with lupin grain results in a rapid increase in the frequency of LH pulses; these pulses then dissipate in 3-4 weeks, despite continued testicular and body growth (Martin ef al., 1994a, b). The effect of improved nutrition in the present experiment was delayed rather than acute, and the dependence upon season contrasts with the situation in Merino rams in which the response of $\mathrm{LH}$ to enhanced nutrition has been observed at all times of the year (GB Martin, unpublished). This difference in the role of season in determining the $\mathrm{LH}$ response to improved nutrition may reflect differences in the extent of photoperiodic regulation of the gonadotrophic axis. Cashmere goats are more strongly seasonal than are Merino sheep and it is possible that the extent of photoperiodic inhibition of the gonadotrophic axis during winter and spring precludes responses to nutrition, while in the relatively nonseasonal Merino, photoperiodic inhibition is weak and able to be overrridden by nutritional stimuli. The effect of diet on testosterone secretion was not related to the effect on testicular size, suggesting that diet-induced testicular growth does not alter Leydig cell function, as appears to be the case in the Merino, ram (Martin et al., 1987, 1994b). The effects of diet on odour score were of greater magnitude and duration than those on sebaceous gland size. This probably results from greater accumulation of sebum in the fleece of bucks fed the highquality diet, given the longer period of sebaceous gland enlargement in response to this treatment, and the absence of weathering by sunlight and rainfall.

The effect of diet on FSH concentration was less pronounced than for $\mathrm{LH}$, although there was evidence of an earlier peak in FSH concentration in bucks on the high-quality diet, consistent with the advancement of the seasonal rise in $\mathrm{LH}$ concentration. However, FSH concentration only differed significantly between diets in the later stages of the experiment at a time when LH concentrations were not affected, suggesting differential regulation of $\mathrm{FSH}$ and $\mathrm{LH}$ secretion by nutrition. It is not clear why significant differences in FSH concentration were restricted to this period. While there was no significant response to nutrition during the early months of the experiment, there was a trend towards higher FSH concentrations in the High treatment group, consistent with the observation that supplemental nutrition increases FSH concentrations in plasma of rams (Martin et al., 1994b).

Although the effects of both season and diet on testosterone concentration were closely associated with changes in LH concentration, the effects on testicular growth appeared to be less dependent on changes in gonadotrophin concentrations. The only consistently strong correlates with testicular growth, within and across treatments, were body growth and voluntary intake of feed, indicating a dependence upon the metabolic status of the animal. The acute effect of nutrition on testicular mass during the first few months of the experiment was not related to changes in either LH or FSH concentration. Similarly, the long-term difference between nutritional treatments in testicular mass was maintained during periods when concentrations of these hormones did not differ. It would appear, then, that the effects of diet on testicular mass are mediated primarily by metabolic signals acting independently of changes in gonadotrophin concentrations. The close association between seasonal changes in body and testicular mass suggests that the seasonal testicular cycle could be similarly mediated, being a secondary response to the seasonal appetite or growth cycle. However, the seasonal cycle of testicular growth was also associated with FSH concentration in bucks fed the low-quality diet and, for the latter part of the experiment, in bucks fed the high-quality diet (the early part of the cycle being clearly disrupted by the acute testicular response to this diet). This finding is consistent with the important role that FSH plays in regulating spermatogenesis in rams (Courot and Ortavant, 1981; Kilgour et al., 1994) and indicates that FSH may be involved in regulating the seasonal testicular cycle in goat bucks, as appears to be the case in rams (Lincoln, 1989). Nevertheless, the clear response of the testis to metabolic changes, independently of changes in gonadotrophin concentrations, suggests that the main factor driving the seasonal testicular cycle is the seasonal appetite or growth cycle.

Testicular size is a good predictor of sperm production in most species (Amann, 1970), including goats (Walkden-Brown et al., in press), and increases in testicular mass induced by improved nutrition in rams are associated with even greater increases in sperm production (Oldham et al., 1978). If we assume that changes in testicular size during the experiment were associated with changes in the spermatogenic capability of the bucks, then there was clear dissociation between the effects of diet on the testosterone-secreting and the spermatogenic functions of the testis during winter and spring (Figs 2c, $3 b)$. Nutritionally induced dissociation between testicular growth and testosterone secretion also occurs in Merino rams (Ritar et al., 1984; Martin et al., 1987; Martin et al., 1994a, b), and may be a characteristic of male ruminants living in environments where food supply is erratic or out of phase with normal photoperiodic responses. In cashmere bucks, derived from feral animals living in semi-arid central Australia, such dissociation may allow testicular development in response to changing nutrition to precede behavioural responses induced by testosterone, ensuring that the testes are well developed by the time of mating.

The results support our original hypotheses that Australian cashmere bucks exhibit considerable reproductive seasonality, and that the expression of this seasonality is modified by the nutritional environment. Of the reproductive variables examined, testosterone concentration, sebaceous gland volume and odour score appeared to be ultimately dependent upon LH secretion and under fairly rigid seasonal control (probably photoperiodic), with the effects of enhanced nutrition limited to periods when seasonal inhibition is waning. However, changes 
in testicular mass (and therefore sperm production) appeared to be driven primarily by changes in the voluntary intake of feed and in growth, often independently of changes in gonadotrophin concentration. Enhanced nutrition is thus able to induce rapid testicular growth, but not increased testosterone production, during winter and spring when photoperiodic inhibition of the hypothalamo-pituitary-testicular axis is maximal.

This work was supported by the Rural Credits Development Fund (Project NSWDA/8932). The authors thank G. Allen, K. Fredrickson, the late D. Wallace, R. B. Lewis, K. Watson and B. Outerbridge for assistance with animal handling and management, J. Downing and D. Palakis for assistance with radioimmunoassays, and W. A. Taylor for preparing the histological sections. The reagents for the FSH assay were kindly provided by the National Institute of Diabetes, Digestive and Kidney Disease, the Center for Population Research of the National Institute of Child Health, the Agricultural Research Service of the US Department of Agriculture, and the University of Maryland School of Medicine.

\section{References}

Amann RP (1970) Sperm production rates. In The Testis Vol. 1: Development Anatomy and Physiology pp 433-481 Eds WR Gromes, NL Vandemark and AD Johnson. Academic Press, London

Beauchamp GK, Doty RL, Moulton DG and Mugford RA (1976) The pheromone concept in mammalian chemical communication: a critique. In Mammalian Olfaction Reproductive Processes and Behaviour pp 143-160 Ed. RL Doty. Academic Press, London

Bissonnette TH (1941) Experimental modification of breeding cycles in goats Physiology and Zoology 14 379-383

Bronson FH (1985) Mammalian reproduction: an ecological perspective Biology of Reproduction 32 1-26

Chemineau P (1987) Possibilities for using bucks to stimulate ovarian and oestrous cycles in anovulatory goats - a review Livestock Production Science 17 135-147

Clarke JR (1981) Physiological problems of seasonal breeding in eutherian mammals Oxford Reviews of Reproductive Biology $3244-312$

Claus R, Over R and Dehnhard M (1990) Effect of male odour on LH secretion and the induction of ovulation in seasonally anoestrous goats Animal Reproduction Science 22 27-38

Cleveland WS (1981) LOWESs: a program for smoothing scatterplots by robust locally weighted regression The American Statistician 3554

Coblentz BE (1986) Functions of scent-urination in ungulates with special reference to feral goats (Capra hircus L) The American Nafuralist 110 549-557

Courot $\mathbf{M}$ and Ortavant $\mathbf{R}$ (1981) Endocrine control of spermatogenesis in the ram Journal of Reproduction and Fertility Supplement 30 47-60

Delgadillo JA and Chemineau P (1992) Abolition of the seasonal release of luteinizing hormone and testosterone in Alpine male goats (Capra hircus) by short photoperiodic cycles Journal of Reproduction and Fertility 94 45-55

D’Occhio MJ and Brooks DE (1983) Seasonal changes in plasma testosterone concentration and mating activity in Border Leicester, Poll, Dorset, Romney and Suffolk rams Australian Joumal of Experimental Agriculture and Animal Husbandry 23 248-253

Ebling FJ (1957) The action of testosterone on the sebaceous glands and epidermis in castrated and hypophysectomized male rats Journal of Endocrinology 15 297-306

Gonzalez-Stagnaro C (1983) Comportamiento reproductivo de las razas locales de ruminantes en el Tropico Americano. In Reproduction des Ruminants en Zone Tropicale Reunion Internationale pp 1-80. INRA Publications, Versailles

Harrington GN (1982) The feral goat. Goats for Meat and Fibre in Australia. Standing Committee for Agriculture Technical Report Series No. 11, pp I-73 CSIRO, Canberra

Henniawati, (1993) Factors Affecting Ovulatory Activity in the Australian Cashmere Goat, PhD Thesis, University of Queensland

Howland BE, Sanford LM and Palmer WM (1985) Changes in the serum levels of $\mathrm{LH}, \mathrm{FSH}$, prolactin, testosterone and cortisol associated with season and mating in male pygmy goats Journal of Andrology 6 89-96
I'Anson H, Foster DL, Foxcroft GR and Booth PJ (1991) Nutrition and reprodution Oxford Reviews of Reproductive Biology 13 239-311

Irby DC, Kerr JB, Risbridger GP and de Kretser DM (1984) Seasonally and experimentally induced changes in testicular function of the Australian bush rat (Rattus fuscipes) Journal of Reproduction and Fertility 70 657-666

Jenkinson DM, Blackburn PS and Proudfoot R (1967) Seasonal changes in the skin glands of the goat British Veterinary Journal 123 541-549

Kilgour RJ, Courot M, Pisselet C, Dubois MP and Sairam MR (1994) Inhibition of FSH but not LH affects spermatogenesis in the mature ram Animal Reproduction Science 34 253-264

Lincoln GA (1989) Seasonal aspects of testicular function. In The Testis pp 329-385 Eds H Burger and D de Krester. Raven Press, New York

Lincoln GA and Short RV (1980) Seasonal breeding: nature's contraceptive Recent Progress in Hormonal Research 36 1-52

Lincoln GA, Lincoln CE and McNeilly AS (1990) Seasonal cycles in blood plasma concentration of FSH, inhibin and testosterone and testicular size in rams of wild feral and domesticated breeds of sheep Journal of Reproduction and Fertility $\mathbf{8 8} 623-633$

Maddocks IG and Jackson L (1988) Structural studies of sheep, cattle and goat skin CSIRO Division of Animal Production, Sydney.

Martin GB, Sutherland SRD and Lindsay DR (1987) Effects of nutritional supplements on testicular size and the secretion of $\mathrm{LH}$ and testosterone in Merino and Booroola rams Animal Reproduction Science 12 267-281

Martin GB, Walkden-Brown SW, Boukhliq R, Tjondronegoro S, Miller DW, Fisher JS, Hötzel MJ, Restall BJ and Adams NR (1994a) Non-photoperiodic inputs into seasonal breeding in male ruminants. In Perspectives in Comparative Endocrinology pp 574-585 Eds KG Davey et al. National Research Council of Canada, Ottawa

Martin GB, Tjondronegoro S and Blackberry MA (1994b) Effects of nutrition on testicular size and the concentrations of gonadotrophins, testosterone and inhibin in plasma of mature male sheep Journal of Reproduction and Fertility 101 121-128

Miller DW and Martin GB (1993) Increases in ovulation rate and gonadotrophin concentration in goats and Merino sheep after treatment with bovine follicular fluid Animal Reproduction Science 31 225-236

Muduuli DS, Sanford LM, Palmer WM and Howland BE (1979) Secretory patterns and circadian and seasonal changes in luteinizing hormone, follicle stimulating hormone, prolactin and testosterone in the male Pygmy goat Journal of Animal Science 49 543-553

Müller-Schwarze D (1991) The chemical ecology of ungulates Applied Animal Behavioural Science 29 389-402

Oldham CM, Adams NR, Gherhadi PB, Lindsay DR and Mackintosh JB (1978) The influence of level of feed intake on sperm-producing capacity of testicular tissue in the ram Australian Journal of Agricultural Research 29 173-179

Restall BJ (1992) Seasonal variation in reproductive activity in Australian goats Animal Reproduction Science 27 305-318

Restall BJ and Pattie WA (1989) The inheritance of cashmere in Australian goats. I: Characteristics of the base population and the effects of environmental factors Livestock Production Science 21 157-172

Ritar AJ (1991) Seasonal changes in LH androgens and testes in the male Angora goat Theriogenology 36 959-971

Ritar AJ, Adams NR and Sanders MR (1984) Effect of lupin feeding on LH, testosterone and testes. In Reproduction in Sheep pp. 76-78 Eds DR Lindsay and DT Pearce. Australian Academy of Science, Canberra

Sasada H, Sugiyama T, Yamashita K and Masaki J (1983) Identification of specific odour components in mature male goats during the breeding season Japanese Journal of Zootechnical Science 54 401-408

Shelton M (1980) Goats: influence of various exteroceptive factors on initiation of estrus and ovulation International Goat and Sheep Research 1 156-162

Walkden-Brown SW, Restall BJ and Henniawati (1993) The male effect in Australian cashmere goats. 3: Enhancement with buck nutrition and use of oestrous females Animal Reproduction Science 32 69-84

Walkden-Brown SW, Norton BW and Restall BJ (1994a) Seasonal variation in voluntary feed intake in cashmere bucks fed ad libitum diets of low or high quality Australian Journal of Agricultural Research 45 355-366

Walkden-Brown SW, Restall BJ, Norton BW and Scaramuzzi RJ (1994b) The 'female effect' in Australian cashmere goats: effect of season and diet quality on the $\mathrm{LH}$ and testosterone response of bucks to oestrous does Journal of Reproduction and Fertility 100 521-531 
Walkden-Brown SW, Restall BJ and Taylor WA Testicular and epididymal sperm content in Australian cashmere bucks: seasonal variation and prediction from in vivo measurements Reproduction Fertility and Development (in press)

Wayne NL and Rissman EF (1990) Effects of photoperiod and social variables on reproduction and growth in the male musk shrew (Suncus marinus) Journal of Reproduction and Fertility Supplement 89 707-715
Wayne NL, Wade GN and Rissman EF (1991) Effects of food restriction and social cues on sexual maturation and growth in male musk shrews (Suncus murinus) Journal of Reproduction and Fertility 91 385-392

Weibel ER, Kistler GS and Scherle WF (1966) Practical stereological methods for morphometric cytology Journal of Cellular Biology 30 23-38

Wilkinson L (1990) sYSTAT: The system for statistics. SYSTAT Inc, Evanson, IL 